Sharif University of Technology
Scientia Iranica
Transactions E: Industrial Engineering
hCIENTIA

\title{
Hybrid fuzzy-stochastic approach to multi-product, multi-period, and multi-resource master production scheduling problem: Case of a polyethylene pipe and fitting manufacturer
}

\author{
S.H. Razavi Hajiagha ${ }^{a, *}$, Sh. Sadat Hashemi ${ }^{\text {b }}$, and M. Sadeghic \\ a. Department of Management, Khatam University, Tehran, Iran. \\ b. Department of Management, Saramadan Andishe Avina Co., Tehran, Iran. \\ c. Industrial Management Group, Faculty of Management and Accounting, Allameh Tabatabaei University, Tehran, Iran. \\ Received 22 November 2016; received in revised form 16 October 2017; accepted 23 April 2018
}

\author{
KEYWORDS \\ Master production \\ scheduling; \\ Stochastic demand; \\ Chance constrained \\ programming; \\ Fuzzy set theory.
}

\begin{abstract}
Master production scheduling is an effective phase of production planning, which ends in production scheduling and magnitude of different products in a company. This problem requires investigating a wide range of parameters, regarding demand, manufacturing resource usage, and costs. Uncertainty is an intrinsic characteristic of these parameters. In this paper, a model is developed for master production scheduling under uncertainty, in which demands, as time-dependent variables, are considered as stochastic variables, while cost and utilization parameters, with cognitive ambiguity, are expressed as fuzzy numbers. A hybrid approach is also proposed to solve the extended model. The application of the proposed method is examined in a practical problem of a polyethylene pipe and fitting Co. in Iran. The result showed a high degree of applicability.
\end{abstract}

(C) 2019 Sharif University of Technology. All rights reserved.

\section{Introduction}

Master Production Scheduling (MPS) is one of the most important activities in production planning and control $[1,2]$. It is a mid-term phase in planning, which translates the long-term aggregate production planning to a plan determining production scheduling and magnitude of different products. MPS coordinates market demand with internal resources of the company [3]. The main goal of MPS establishment is to increase

\footnotetext{
*. Corresponding author.

E-mail addresses: h.razavi@khatam.ac.ir (S.H. Razavi Hajiagha); shide_hashemi@yahoo.com (Sh. Sadat Hashemi); m.r.sadeghi@st.atu.ac.ir (M.Sadeghi)
}

doi: $10.24200 /$ sci. 2018.20329 the productivity of production resources, i.e., human resources, costs, and production facilities, as well as some important competitive criteria for the company, e.g., profit, service level, etc.

MPS converts the strategic planning defined in a production plan into the tactical operation execution. According to American Production and Inventory Control Society (APICS), MPS is the declaration of what the company expects to be produced in terms of configuration, quantities, and specific dates [4]. It drives the Material Requirement Planning (MRP) and other subsequent activities of a manufacturing company. Figure 1 shows the relation between MPS and the other important activities in production management. Therefore, MPS is a series of managerial decisions that should be made by considering some important issues like forecasted demands, pending orders, material 


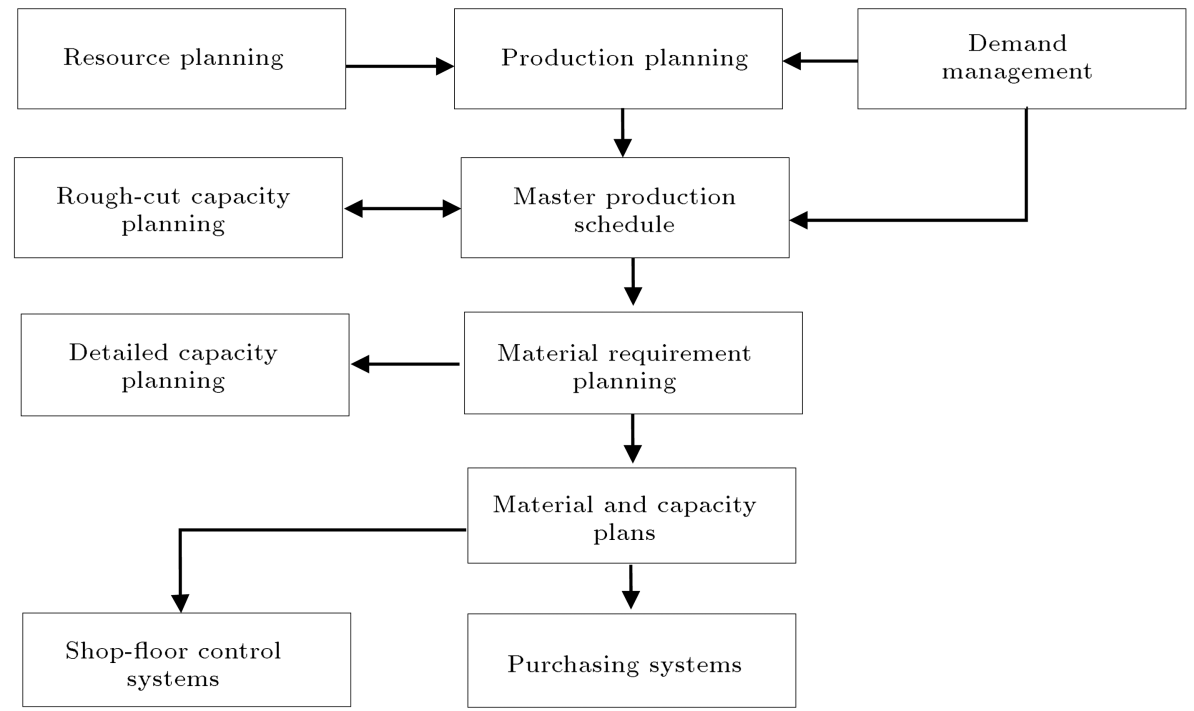

Figure 1. The relation between production management activities.

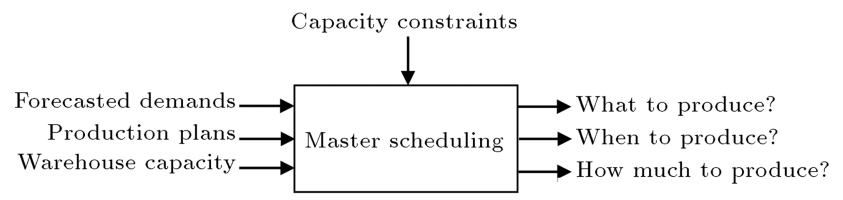

Figure 2. Inputs to and outputs of MPS.

availability, available capacity, managerial policies, and goals. Figure 2 shows the important inputs, outputs, and considerations in an MPS process.

Using optimization approach is one of the conventional approaches to solving the MPS problems, like many other production management problems. Modeling the problem as an optimization model and then solving the model are the main steps in applying the optimization approach. To model the MPS problem, many objectives can be involved, which may conflict with each other. On the other hand, there can be many constraints involved in modeling and solving the MPS problem. The objective considered frequently in the previous studies has been the minimization of production costs, inventory costs, and backordering costs, and the main constraint involved in model development has been meeting the demands, inventory related constraints, and resource related constraints.

The application of mathematical programming to MPS problems is a well-known and accepted approach. Houghton and Portugal [5] presented an analytic framework for optimum production planning. Vasant [6] proposed a fuzzy linear programming methodology and applied it to a real-life industrial production planning problem. Wang and $\mathrm{Wu}$ [7] presented a framework to solve multi-period, multi-product, and multi-resource MPS problem. Emani Vieira and Ribas [8] presented a multi-objective model and its solution based on simulated annealing. Sawik [9] presented a multi- objective production scheduling in make-to-order manufacturing and proposed a lexicographic approach to solving the model. Soares and Vieira [3] presented and developed the application of genetic algorithm to solve the mathematical problem of MPS. Lei [10] reviewed the literature on production scheduling problems. Leu et al. [11] developed a linear programming model for mid-term planning, considering the issues in production and material requirement planning. Kelbel and Hanzalek [12] developed an application of constraint programming to production scheduling with earliness and tardiness penalties. Alfieri et al. [13] proposed an approach based on production process knowledge to extract scheduling information from an aggregate production plan in order to support material procurement. Alfieri et al. [14] proposed a two-stage stochastic programming project scheduling approach to supporting production planning. Ballestin et al. [15] modeled the production planning problem as a project scheduling problem. Moon et al. [16] considered electricity consumption costs in production scheduling as well as two objectives to minimize makespan of production and time-dependent electricity cost. The hierarchical planning decisions are made in a way that the production planning is carried out by the integrated models at first, and the scheduling operations are then performed. In this regard, the highest complexity comes from the difficulties of synchronization of the production planning with scheduling. Sun et al. [17] planned a program to reduce the delivery time of cement manufacturing product, which is a key factor in this industry. They designed an MPS model based on $\mathrm{BOM}$ and then, proposed an approach to reducing the delivery time.

Sahebjamnia et al. [18] developed a fuzzy stochastic multi-objective linear programing model as a novel 
fuzzy stochastic programming for a multi-level, capacitated lot-sizing problem in a furniture company. They treated the demand- and process-related parameters as fuzzy stochastic parameters. Kim and Lee [19] proposed an iterative approach to achieving the synchronization in order to coordinate the input and output quantities of the production plan while generating a schedule. For this purpose, they utilized the inputoutput quantity as well as the production quantity as coordination factor [19]. In another paper, Menezes et al. [20] introduced a hierarchical approach to solving the production planning and scheduling problems. In this mathematical model, when scheduling is not feasible, capacity information is forwarded to production planning to modify and show the use of new tasks. This method was proposed and is used for transportation of products and in stock conditions, particularly the situations which involve the flow of products in bulk cargo (iron ore, coal, and grains) terminals. Martinez et al. [21] worked on molded pulp packaging as a sample of multi-stage, multi period, and multi-product manufacturing type. The problem was solved with a mixed integer programing model. For multi-objective optimization of master production scheduling problem, Radhikan et al. [22] used Jaya algorithm as a metaheuristic problem solving method, which required only common control parameters, not any algorithm-specific control ones. Cho and Jeong [23] used genetic algorithm as another meta-heuristic production planning and scheduling method to solve Bi-objective problems. Farrokh et al. [24] proposed a novel robust fuzzy stochastic programming approach in the loop supply chain network. Gramani et al. [25] proposed an exact method of production planning and compared their findings with industrial practices. Considering the above studies, the main contributions of the current paper can be fitting a real statistical distribution to demand data and describing the cognitive hesitancy of costs and prices by using fuzzy sets. A hybrid approach for the fuzzy-stochastic programming model is proposed to solve the considered problem. Also, the material requirement planning is integrated in the production planning problem to determine the magnitude and scheduling of material procurement along with developing the production plan.

Defining the parameters while using the optimization approach is a big challenge in modeling. The defined parameters, which are used in model development, should conform to the real world, because using the crisp numbers instead of parameters leads to impracticability of the established model. In fact, uncertainty is an intrinsic feature of real-world applications. Usually, the uncertainty can occur due to (1) partial or (2) approximate information [26]. Using the fuzzy logic, researchers apply grey numbers and stochastic programming as a solution to this kind of challenge.
Each type of uncertainty has its own characteristics and is appropriate for special cases. While probability is concerned with occurrence of well-defined events, fuzzy sets deal with gradual concepts and describe their boundaries [27]. In production planning framework, the behavior of demand along with time can be assessed with a probability distribution, while the ambiguity of cost parameters is often due to lack of knowledge and it does not behave stochastically. Therefore, as it is convenient, the demands are taken into account as stochastic variables, while cost parameters are considered as fuzzy numbers. The aim of this paper is to combine both of them in a singular model.

Demand uncertainty has been considered in some previous studies on MPS. Tang and Grubbstrom [28] presented an MPS model under demand uncertainty. Fleten and Kristoffersen [29] applied stochastic programming to production planning. Feng et al. [30] studied the MPS problem for single end-product with time-varying demand uncertainty and supply capacity. Liang [31] developed a fuzzy multi-objective linear model to solve multi-product and multi-time-period production/distribution problems. Supriyanto and Noche [32] proposed a methodology for MPS problems in which uncertainty was considered under fuzzy information. Körpeoğlu et al. [33] used a multi-stage stochastic programming approach, considering several demand scenarios. Also, Mula et al. [34] reviewed production planning under uncertainty.

In this paper, the main idea is to consider the fuzziness of parameters and objectives as well as stochastic customer demands in model establishment. Hybrid uncertain methods have extensively been applied in different fields [35-38]. After model development, an interactive method based on the existing techniques in the optimization literature is developed to solve the proposed model. This paper is organized as follows. Section 2 provides a brief review of the used methods in this paper. The problem modeling is discussed in Section 3. Section 4 involves the problem solving approach and in Section 5, a real-world case study of the proposed method is presented. Finally, Section 6 contains the conclusion.

\section{Preliminaries}

\subsection{Chance constrained programming}

Chance Constrained Programming (CCP) was introduced by Charnes and Cooper [39] as a conceptual framework to deal with stochastic programming. This model considers the case when objective function is a deterministic function, while constraints are expressed in stochastic form. Suppose the following problem:

Maximize $\quad f(c, X)$, 
Subject to: $\hat{A} X \leq \hat{b}$,

$$
X \geq 0
$$

where $f(c, X)$ is the objective function, $X$ is the decision vector, $c$ is the vector of objective coefficients, $\hat{A}$ is the stochastic matrix of constraint coefficients, and $\hat{b}$ is the stochastic right-hand-side vector. The CCP model maximizes the objective function subjected to constraints, which must be satisfied at a prescribed level of probability. A typical CCP model can be expressed as follows:

$$
\text { Maximize } \quad f(c, X),
$$$$
\text { Subject to: } \operatorname{Pr}(\hat{A} X \leq \hat{b}) \geq \alpha, \quad \alpha \in[0,1]
$$

$$
X \geq 0 .
$$

Here, $\alpha$ is the prescribed level of probability $[39,40]$.

\subsection{Fuzzy sets}

Fuzzy set theory was introduced by Zadeh [41] and has been developed and applied to a wide variety of practical problems. A fuzzy set $\tilde{A}$ in the universe $X$ is characterized by its membership function $\mu_{\tilde{A}}: X \rightarrow$ $[0,1]$, where $\mu_{\tilde{A}}(x), x \in X$ denotes the membership degree of $x$ to $\tilde{A}$.

A fuzzy number is a fuzzy set, $\tilde{a}$, on the real line, $R$, whose membership function, $\mu_{\tilde{a}}$, is a convex, upper semi-continuous function. A trapezoidal fuzzy number is denoted by $\tilde{a}=\left(a_{1}, a_{2}, a_{3}, a_{4}\right)$ whose membership function is as follows [42]:

$$
\mu_{\tilde{a}}(x)= \begin{cases}\left(x-a_{1}\right) /\left(a_{2}-a_{1}\right), & \text { if } a_{1} \leq x \leq a_{2} \\ 1, & \text { if } a_{2} \leq x \leq a_{3} \\ \left(x-a_{4}\right) /\left(a_{3}-a_{4}\right), & \text { if } a_{3} \leq x \leq a_{4} \\ 0, & \text { otherwise }\end{cases}
$$

A special type of trapezoidal fuzzy number is a triangular one with $a_{2}=a_{3}$, and it can be shown in the form of $\tilde{a}=\left(a_{1}, a_{2}, a_{3}\right)$. These two types of fuzzy numbers, i.e., trapezoidal and triangular, are widely applied in decision making and planning type problems.

The algebraic operations on fuzzy numbers are well-known and have been reviewed in many references $[43,44]$. Therefore, they are not repeated in this paper.

\section{Model construction}

In this paper, the MPS problem is formulated in the form of a mathematical programming model in order to minimize total production cost, considering different limitations. Emani Vieira \& Ribas [8] and Soares \& Vieira [3] regarded four considerations in formulating an MPS problem:

1. Minimizing the inventory level;

2. Minimizing the unfulfilled requirements (demand);

3. Minimizing the inventory below the safety stock level;

4. Minimizing the quantity of additional needed resources.

In the proposed model, two additional aspects are also considered:

5. Minimization of production cost;

6. Minimization of resource procurement cost.

\subsection{Parameters, variables, and notations}

The following parameters are used in model construction; " $\wedge$ " denotes the stochastic nature and " " denotes the fuzziness of notations.

\section{Problem parameters}

$K \quad$ Variety of products;

$T \quad$ Number of planning periods;

$R \quad$ Number of productive resources;

$T H_{t} \quad$ Time length of each period $t$, $t=1,2, \cdots, T$

TH Total planning horizon;

$\mathrm{POH}_{k} \quad$ On-hand inventory of product type $k$ in the first period;

$\hat{d}_{k t} \quad$ Gross requirements for product $k$ at period $t$ with expected value of $\mu_{k t}$ and variance $\sigma_{k t}^{2}$;

$c_{r 0} \quad$ Available capacity at resource $r$ in the first period;

$\tilde{a}_{r k} \quad$ Capacity used from resource $r$ to produce one unit of product $k$;

$\tilde{c}_{k}^{p} \quad$ Unit production costs of product $k$;

$\tilde{c}_{k}^{h} \quad$ Unit holding costs of product $k$;

$\tilde{c}_{k}^{b} \quad$ Penalty costs for each unit of requirement of product $k$ that is not met;

$\tilde{u}_{r t}^{o} \quad$ Unit costs to obtain one unit of resource $r$ at period $t$;

$\tilde{c}_{b s s k t} \quad$ Unit costs for each unit of product $k$ below safety stock at period $t$;

$\tilde{h}_{r t} \quad$ Unit holding costs of resource $r$ at period $t$;

$S S_{k t} \quad$ Safety inventory level for product $k$ at period $t$. 


\section{Decision variables:}

$x_{k t} \quad$ Total quantity to be manufactured from product $k$ at period $t$;

$i_{k t} \quad$ Initial inventory level of product $k$ at period $t$;

$f_{k t} \quad$ Final inventory level of product $k$ at period $t$;

$c_{r t} \quad$ The quantity of resource $r$ that must be supplied at period $t$;

$s_{r t} \quad$ Units of additional resource $r$ that remain unused at period $t$;

$A I L_{k t} \quad$ Average inventory level of product $k$ at period $t$;

$B S S_{k t} \quad$ The average quantity below safety inventory level for product $k$ at period $t$;

$r_{k t} \quad$ Requirements not met for product $k$ at period $t$.

\subsection{Objective function}

Several objectives can be considered in formulating a production planning problem. These objectives mainly imply some costs to the manufacturer. For instance, beyond the common production costs associated with the direct material, manpower, and overhead, a manufacturer tolerates some costs due to over- or underinventory and so on. In this paper, total production cost is considered as an objective that the manufacturer seeks to minimize. According to the defined parameters and variables, the objective function of MPS problem can be developed as follows:

$$
\begin{aligned}
\text { Minimize } \tilde{Z}= & \sum_{k=1}^{K} \sum_{t=1}^{T}\left(\tilde{c}_{k}^{p} x_{k t}+\tilde{c}_{k}^{h} A I L_{k t}+\tilde{c}_{k}^{b} r_{k t}\right) \\
& +\sum_{k=1}^{K} \sum_{t=1}^{T} \tilde{u}_{r t}^{o} c_{r t}+\sum_{r=1}^{R} \sum_{t=1}^{T} \tilde{h}_{r t} s_{r t} \\
& +\sum_{k=1}^{K} \sum_{t=1}^{T} \tilde{c}_{b s s k t} B S S_{k t} .
\end{aligned}
$$

The first term of Eq. (4) represents the production costs of products along with their induced holding cost due to positive amounts of inventory level and the penalty cost because of the inability to satisfy the customers' demand. While the second term expresses the procurement costs in the whole planning horizon, the third term illustrates the holding cost due to surplus amount of the obtained resources. The last term is the penalty cost, which occurs due to inventory level getting under safety stock in planning horizon.

\subsection{Constraints of the model}

The main constraints that should be satisfied when minimizing the defined objective function are related to inventory, demand, safety stock, and resource utilization:

- Inventory related constraints: for the $k$ th product at period $t$, Eq. (5) should be satisfied:

$$
i_{k 1}=P O H_{k}, \quad k=1,2, \cdots, K,
$$

and:

$$
i_{k t}=f_{k t-1} \text {. }
$$

Therefore, the average inventory level for each period $t$ and each product $k$ will be as follows:

$$
A I L_{k t}=\frac{i_{k t}+f_{k t}}{2} \text {. }
$$

- Demand related constraints: for the $k$ th product at period $t$, Eq. (8) should be satisfied:

$$
x_{k t}+i_{k t}+r_{k t}-f_{k t} \geq \hat{d}_{k t}, \quad k=1,2, \cdots, K .
$$

- The inventory level of each product remains below the defined safety stock by the satisfaction of Eq. (9):

$$
B S S_{k t}=\max \left[0, S S_{k t}-f_{k t}\right], \quad k=1,2, \cdots, K .
$$

- The resource utilization related constraints are defined by Eq. (10):

$$
\sum_{k=1}^{K} \tilde{a}_{k r} x_{k t}-s_{r t}=c_{r t}-s_{r(t-1)}, \quad r=1,2, \cdots, R .
$$

Therefore, the fuzzy-stochastic MPS model can be demonstrated as follows:

$$
\text { Minimize } \begin{aligned}
\tilde{C}= & \sum_{k=1}^{K} \sum_{t=1}^{T}\left(\tilde{c}_{k}^{p} x_{k t}+\tilde{c}_{k}^{h} A I L_{k t}+\tilde{c}_{k}^{b} r_{k t}\right) \\
& +\sum_{r=1}^{R} \sum_{t=1}^{T} \tilde{u}_{r t}^{o} c_{r t}+\sum_{r=1}^{R} \sum_{t=1}^{T} \tilde{h}_{r t} s_{r t} \\
& +\sum_{k=1}^{K} \sum_{t=1}^{T} \tilde{c}_{b s s t} B S S_{k t} .
\end{aligned}
$$

Subject to:

(i) $i_{k 1}=P O H_{k}$,

(ii) $i_{k t}=f_{k t-1}$,

(iii) $x_{k t}+i_{k t}+r_{k t}-f_{k t} \geq \hat{d}_{k t}$,

(iv) $B S S_{k t} \geq S S_{k t}-f_{k t}$,

(v) $\sum_{k=1}^{K} \tilde{a}_{k r} x_{k t}+s_{r t}=c_{r t}+s_{r(t-1)}$,

$x_{k t}, i_{k t}, f_{k t}, r_{k t}, B S S_{k t}, c_{r t}, s_{r t} \geq 0$,

$k=1,2, \cdots, K ; \quad t=1,2, \cdots, T$.

In Eq. (11), the set of constraints (iii) is stochastic, and the objective function and set of constraints (v) are of the fuzzy type. 


\section{Solving approach}

The proposed optimization model for MPS problems, i.e., Eq. (11), is a combined stochastic-fuzzy linear programming model. Chance constrained programming [39] is a well-known method to solve stochastic programming problems, while there are some methods to solve fuzzy linear programming problems [45-49]. Since the chance constrained programming method solves the problems in different levels of probability, i.e., $\alpha_{i}, i=1,2, \cdots, l$, the applied method to solve hybrid problems will be constructed based on different significance levels. The main advantage of chance constrained programming is its ability to handle and analyze different statistical distributions. Also, there are not any limitations on randomness of objective function, constraints, and right-hand-side values. In this regard, scholars have proposed chance constrained programming as a powerful tool of handling stochastic optimization problems [50-52].

Suppose that the decision maker determines the satisfaction level $\alpha$. The stochastic constraints (iii) can be analyzed based on chance constrained programming; If $\hat{d}_{k t}$ is a random variable which follows a probability distribution like $f$, then these constraints can be demonstrated as Eq. (12) in the satisfaction level $\alpha$ :

$$
\operatorname{Pr}\left(\hat{d}_{k t} \leq x_{k t}+i_{k t}-r_{k t}-f_{k t}\right) \geq \alpha
$$

If $f_{\alpha}^{-1}$ has a value such that $\operatorname{Pr}\left(\hat{d}_{k t} \leq f_{\alpha}^{-1}\right)=\alpha$, then Eq. (12) is equivalent to Eq. (13):

$$
x_{k t}+i_{k t}+r_{k t}-f_{k t} \geq f_{\alpha}^{-1}
$$

By defining Eq. (13), the stochastic constraints (iii) can be transformed into a set of linear constraints. Now, a method using the concept of $\alpha$-cuts is developed to deal with the fuzziness. If $\tilde{A}$ is a fuzzy set in universe $U$ characterized by membership function $\mu_{\tilde{A}}$, its $\alpha$-cut is defined as $\tilde{A}_{\alpha}=\left\{x \in U \mid \mu_{\tilde{A}}(x) \geq \alpha\right\}$. The $\alpha$-cuts can be shown as crisp intervals, which are called $\alpha$-level interval:

$$
\begin{aligned}
\tilde{A}_{\alpha}= & {\left[A_{\alpha}^{l}, A_{\alpha}^{u}\right]=\left[\min _{x}\left\{x \in U \mid \mu_{\tilde{A}}(x) \geq \alpha\right\},\right.} \\
& \left.\max _{x}\left\{x \in U \mid \mu_{\tilde{A}}(x) \geq \alpha\right\}\right] .
\end{aligned}
$$

For a trapezoidal fuzzy number, $\tilde{a}=\left(a_{1}, a_{2}, a_{3}, a_{4}\right)$, its $\alpha$-level interval is determined as $\tilde{a}_{\alpha}=\left(\alpha a_{2},(1-\right.$ $\left.\alpha) a_{1}, \alpha a_{3},(1-\alpha) a_{4}\right)$. Applying the concept of $\alpha$-level interval and probability level $\alpha$ (totally named satisfaction level), the stochastic-fuzzy problem in Eq. (11) is reduced to an equivalent interval linear programming as represented in Eq. (15).

$$
\text { Minimize } \begin{aligned}
\tilde{C}= & \sum_{k=1}^{K} \sum_{t=1}^{T}\left(\left[c_{k}^{p l}, c_{k}^{p u}\right] x_{k t}\right. \\
& \left.+\left[c_{k}^{h l}, c_{k}^{h u}\right] A I L_{k t}+\left[c_{k}^{b l}, c_{k}^{b u}\right] r_{k t}\right) \\
& +\sum_{r=1}^{R} \sum_{t=1}^{T}\left[u_{r t}^{o l}, u_{r t}^{o u}\right] c_{r t} \\
& +\sum_{r=1}^{R} \sum_{t=1}^{T}\left[h_{r t}^{l}, h_{r t}^{u}\right] s_{r t} \\
& +\sum_{k=1}^{K} \sum_{t=1}^{T}\left[c_{b s s k t}^{l}, c_{b s s k t}^{u}\right] B S S_{k t} .
\end{aligned}
$$

Subject to:

(i) $i_{k 1}=P O H_{k}$,

(ii) $i_{k t}=f_{k t-1}$,

(iii) $x_{k t}+i_{k t}+r_{k t}-f_{k t} \geq f_{\alpha}^{-1}$,

(iv) $B S S_{k t} \geq S S_{k t}-f_{k t}$,

(v) $\sum_{k=1}^{K}\left[a_{k t}^{l}, a_{k t}^{u}\right] x_{k t}+s_{r t}=c_{r t}+s_{r(t-1)}$,

$$
\begin{aligned}
& x_{k t}, i_{k t}, f_{k t}, r_{k t}, B S S_{k t}, c_{r t}, s_{r t} \geq 0, \\
& k=1,2, \cdots, K ; \quad t=1,2, \cdots, T .
\end{aligned}
$$

Except for (v) constraints in Eq. (15), all the constraints are crisp. Therefore, a method is required to deal with these constraints. Ishibuchi and Tanaka [53] introduced some order relations to compare interval numbers. Considering their definitions, the following equation is substituted for these constraints:

$$
\sum_{k=1}^{K}\left(\frac{a_{k t}^{l}+a_{k t}^{u}}{2}\right) x_{k t}+s_{r t}=c_{r t}+s_{r(t-1)} .
$$

Replacing Eq. (16) with (v) constraints in Eq. (15), a problem with interval objective function arises. Now, consider the concept of Right-Center (RC) order relation of Ishibuchi and Tanaka [53]. According to this relation, an interval function $[\underline{C}, \bar{C}]$ will be minimized when its upper bound $\bar{C}$ and its center $((\underline{C}+\bar{C}) / 2)$ are minimized. Applying this notion to the objective function of Eq. (15), the upper bound of the objective function is obtained as:

$$
\bar{C}=\sum_{k=1}^{K} \sum_{t=1}^{T}\left(c_{k}^{p u} x_{k t}+c_{k}^{h u} A I L_{k t}+c_{k}^{b u} r_{k t}\right)
$$




$$
\begin{aligned}
+ & \sum_{k=1}^{K} \sum_{t=1}^{T} u_{r t}^{o u} c_{r t}+\sum_{k=1}^{K} \sum_{t=1}^{T} h_{r t}^{u} s_{r t} \\
& \sum_{k=1}^{K} \sum_{t=1}^{T} c_{b s s k t}^{u} B S S_{k t},
\end{aligned}
$$

while its center is:

$$
\begin{aligned}
\frac{\underline{C}+\bar{C}}{2}= & \sum_{k=1}^{K} \sum_{t=1}^{T}\left(\left(\frac{c_{k}^{p l}+c_{k}^{p u}}{2}\right) x_{k t}\right. \\
& \left.+\left(\frac{c_{k}^{h l}+c_{k}^{h u}}{2}\right) A I L_{k t}+\left(\frac{c_{k}^{b l}+c_{k}^{b u}}{2}\right) r_{k t}\right) \\
& +\sum_{r=1}^{R} \sum_{t=1}^{T}\left(\frac{u_{r t}^{o l}+u_{r t}^{o u}}{2}\right) c_{r t} \\
& +\sum_{r=1}^{R} \sum_{t=1}^{T}\left(\frac{h_{r t}^{l}+h_{r t}^{u}}{2}\right) s_{r t} \\
& +\sum_{k=1}^{K} \sum_{t=1}^{T}\left(\frac{c_{b s s k t}^{l}+c_{b s s k t}^{u}}{2}\right) B S S_{k t} . \quad(17
\end{aligned}
$$

Finally, the hybrid stochastic-fuzzy MSP problem in Eq. (14) and its reduced-form interval linear programming problem in Eq. (15) can be restated as a vector minimization problem of the following form:

Minimize $\left(\bar{C}, \frac{C+\bar{C}}{2}\right)$.

Subject to:

$$
\mathrm{FS}:\left\{\begin{array}{l}
i_{k 1}=P O H_{k}, \\
i_{k t}=f_{k t-1}, \\
x_{k t}+i_{k t}+r_{k t}-f_{k t} \geq f_{\alpha}^{-1}, \\
B S S_{k t} \geq S S_{k t}-f_{k t}, \\
\sum_{k=1}^{K}\left(\frac{a_{k t}^{l}+a_{k t}^{u}}{2}\right) x_{k t}+s_{r t}=c_{r t}+s_{r(t-1)}, \\
x_{k t}, i_{k t}, f_{k t}, r_{k t}, B S S_{k t}, c_{r t}, s_{r t} \geq 0, \\
k=1,2, \cdots, K \\
t=1,2, \cdots, T
\end{array}\right.
$$

A goal programming based approach is now developed to solve this problem. The problem seeks to minimize total costs of production; therefore, its goal value will be equal to zero. The soft constraints of the problem are formulated as follows:

$$
\left\{\begin{array}{l}
\bar{C}+d_{1}^{-}-d_{1}^{+}=0 \\
\frac{\underline{C}+\bar{C}}{2}+d_{2}^{-}-d_{2}^{+}=0
\end{array}\right.
$$

Finally, the goal programming formulation of the problems is extended to:

$$
\begin{aligned}
& \text { Minimize } d_{1}^{+}+d_{2}^{+} \\
& \bar{C}+d_{1}^{-}-d_{1}^{+}=0, \\
& \frac{C+\bar{C}}{2}+d_{2}^{-}-d_{2}^{+}=0, \\
& x \in \mathrm{FS}
\end{aligned}
$$

where $x$ represents the solution vector. Solving the above problem will determine the optimal production plan.

Note that for both stochastic and fuzzy constraints, smaller values of $\alpha$ lead to larger feasible regions and the objective function can be improved. Therefore, the decision maker faces two conflicting objectives:

1. To improve the objective function value;

2. To improve the satisfaction level of constraints.

It is notable that since there are different fuzzy parameters in the model, there is not any dependency among the $\alpha$ values of these parameters. However, it seems reasonable that by solving the model in one time, all the $\alpha$ values can be determined equally. The considered $\alpha$ values can be predetermined by the decision maker based on their cognition of the uncertainty. However, Jimenez et al. [47] proposed an interactive procedure in a similar situation. Following Kaufmann and Gil Aluja [54], they applied an eleven-point scale for sufficient distinction between satisfaction levels:

0 Unacceptable solutions

0.1 Practically unacceptable solution

0.2 Almost unacceptable solution

0.3 Very unacceptable solution

0.4 Quite unacceptable solution

0.5 Neither acceptable nor unacceptable solution

0.6 Quite acceptable solution

0.7 Very acceptable solution

0.8 Almost acceptable solution

0.9 Practically acceptable

1 Completely acceptable solution

Firstly, the ordinal linear programming model (20) is solved for each $\alpha_{k}=\alpha_{0}+0.1 k, k=0,1, \cdots,(1-$ $\left.\alpha_{0}\right) / 0.1$. By solving Model (20) for different values of $\alpha$, a set of optimal fuzzy values, $\tilde{C}_{\alpha}^{*}$, will be obtained. To compare these solutions and choose an acceptable 
solution, the Yager [55] method is used. Yager [55] index is defined as:

$$
K_{G}\left(z_{\alpha}^{*}\right)=\frac{\int_{-\infty}^{+\infty} \mu_{G}(x) \cdot \mu_{\alpha}(z) d x}{\int_{-\infty}^{+\infty} \mu_{\alpha}(z) d x},
$$

where the denominator is the area under $\mu_{\alpha}(z)$ and, in the numerator, the possibility of occurrence $\mu_{\alpha}(z)$ of each crisp value $z$ is weighted by its satisfaction degree, $\mu_{G}(x)$, of the goal $G$. This is an extension of the widely accepted center of gravity defuzzification method, using the goal function, $\mu_{G}(x)$, as a weighting value. $K_{G}\left(z_{\alpha}^{*}\right)$ illustrates the compatibility of a decision in satisfaction level, $\alpha$, with the aspiration of the decision maker defined by $\mu_{G}(x)$. To balance the impact of satisfaction level, the fuzzy decision in the assumed satisfaction level is determined by the following membership degree in decision space:

$$
\mu_{D}\left(x_{\alpha}^{*}\right)=\alpha * K_{G}\left(z_{\alpha}^{*}\right)
$$

where $*$ is an operator like minimum, product, etc. The final decision is chosen with the highest membership degree in decision space, that is, $x^{*}$ is chosen when:

$$
\mu_{D}\left(x^{*}\right)=\max _{\alpha} \mu_{D}\left(x_{\alpha}^{*}\right) .
$$

An algorithmic scheme of the above problem can be stated as follows:

1. Prepare the information needed to formulate the problem, Eq. (11); include fuzzy cost parameters, demand statistical distributions, resources usage of products, and maximum available amount of resources;

2. Choose a satisfaction level, $\alpha_{k}=\alpha_{0}+0.1 k, k=$ $0,1, \cdots,\left(1-\alpha_{0}\right) / 0.1$;

3. In the specified satisfaction level, $\alpha_{k}$, transform the stochastic constraints, using Eq. (13), into a set of equivalent linear constraints;

4. Constitute the problem in Eq. (15) by using fuzzy numbers of $\alpha$-cuts;

5. Constitute and solve the problem in Eq. (16) at different $\alpha$-levels and find the most compromising solution using Eqs. (21)-(23).

Figure 3 illustrates the algorithm used to solve the proposed model in a flowchart.

\section{Practical example, a real-world case study}

In this section, an application of the proposed method is presented. The Semnan Polyethylene Pipe and Fitting Co. (SPP and F) was founded in 1994, following the major demand of the polyethylene pipes and irrigation tools for the implementation of under-pressure irrigation, water supply, and gas supply. This company produces many types of polyethylene products, using different types of materials; therefore, it requires a production scheduling program for its products. The SPP and F products include 16 items as follows:

1. Bubbler Net (BN)

2. Dripper Sided Pot (DSP)

3. Easy Block Coupling (EBC)

4. Variable Plastic Nozzles (VPN)

5. Bubbler (B)

6. End Closure (EC)

7. Offtake $(\mathrm{O})$

8. Adaptor (A)

9. Equal tee (E)

10. Drum Dripper (DD)

11. Adjustable Dripper (AD)

12. Spray Jets (SJ)

13. Puncher $(\mathrm{P})$

14. Bubbler Stake (BS)

15. In Line Dripper (ILD)

16. Male Adopter (MA)

The manufacturing process begins with the granular raw materials entered into molding machine. After being melted and shaped, the product will come out of machine. The process continues with packaging and then, the products are stocked. Three types of main raw materials, which are used to produce these products, include the following:

1. PP (polypropylene): Price per $\mathrm{kg}$ is approximated as $(1.5,1.7,2.05) \$$ with a holding cost of $(0.18,0.204,0.246) \$$ per $\mathrm{kg}$;

2. Poly acetal (or poly oxy methylene): Price per $\mathrm{kg}$ is approximated as $(0.65,1,1.4) \$$ with a holding cost of $(0.13,0.2,0.28) \$$ per $\mathrm{kg}$;

3. ABS (acrylonitrile-butadiene-styrene): Price per $\mathrm{kg}$ is approximated as $(3.5,4,5) \$$ with a holding cost of $(0.595,0.68,0.85) \$$ per $\mathrm{kg}$. Also, the company has the capacity for buying and holding 300 tons of material per month.

Figure 4 presents a scheme of SPP and F production shop. The aim of the problem is to determine the production plan for a period of 3 months with 22,21 , and 22 working days, each of which has two 8-hour working shifts. Table 1 shows the information about the operation process of each product. It is notable that the operation time, per product per operation, 


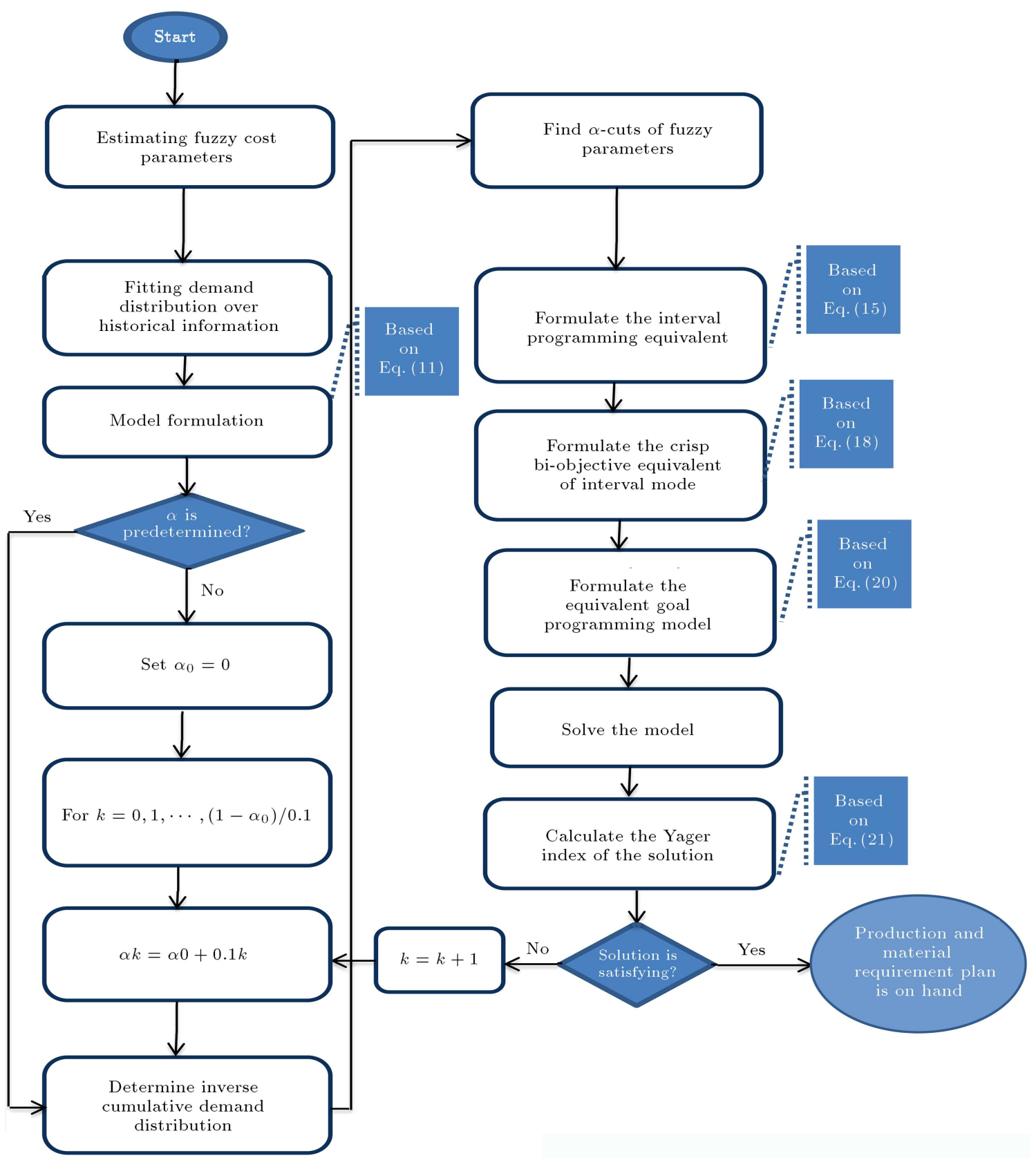

Figure 3. The production shop in SPP and F.

is approximated with a fuzzy number, in which the time variations are considered with a triangular fuzzy number. On the other hand, the material usage of each granular in each product is approximated by considering the approximated material waste and trash, which is characterized with a triangular fuzzy number. The required information about costs regarding each product is given in Table 2 .

The marketing department analyzed the historical data on demand for products and found that the data fitted the appropriate probability distribution on demands per product. Table 3 shows the probability distribution of products for a three-month period.
Initially, a total of sale information for a period of 120 months is analyzed and a probability distribution is fitted to each product demand. Then, the distribution parameters are evaluated for each month by using a Maximum Likelihood Estimation (MLE) method in similar months in previous years.

Model (20) for SPP and F includes 198 variables and 104 constraints. SPP and F managers needed to solve the production planning in three satisfaction levels of $0.7,0.8$, and 1.0. Also, the values of $f_{\alpha}^{-1}$ for probability distributions of Table 3 at different satisfaction levels were determined using MINITAB 16 package. The obtained fuzzy objective functions in 
Table 1. Information about production and operation.

\begin{tabular}{cclccc}
\hline \multirow{2}{*}{ Product } & $\begin{array}{c}\text { Molding machine } \\
\text { (time per sec) }\end{array}$ & $\begin{array}{c}\text { Packaging } \\
\text { (time per sec) }\end{array}$ & $\begin{array}{c}\text { PP } \\
(\mathbf{g r})\end{array}$ & $\begin{array}{c}\text { ABS } \\
(\mathbf{g r})\end{array}$ & $\begin{array}{c}\text { Polyacetal } \\
\text { (gr) }\end{array}$ \\
\hline BN & 2.5 & {$[0.6,0.75,1]$} & 10.72 & - & - \\
DSP & 8.8 & {$[0.6,0.72,0.8]$} & 112 & - & - \\
EBC & 25 & {$[0.6,0.7,0.8]$} & 16.3 & - & - \\
VPN & 22.5 & {$[0.4,0.6,0.75]$} & - & 28 & - \\
B & 27 & {$[0.7,0.8,0.9]$} & - & 25.46 & - \\
EC & 2.75 & {$[0.65,0.75,0.88]$} & 29.28 & - & - \\
O & 4.38 & {$[0.8,0.9,1]$} & 19.2 & - & - \\
A & 13.34 & {$[0.65,0.75,0.85]$} & 21.12 & - & - \\
E & 9.88 & {$[0.55,0.65,0.75]$} & 22.08 & - & - \\
DD & 10 & {$[0.4,0.6,0.75]$} & 23.58 & - & - \\
AD & 19.25 & {$[0.55,0.65,0.75]$} & 28 & - & - \\
SJ & 2.083 & {$[0.45,0.6,0.7]$} & - & - & 9.6 \\
P & 15 & {$[0.7,0.85,0.95]$} & - & 11.44 & - \\
BS & 21.88 & {$[0.5,0.6,0.75]$} & 30.6 & - & - \\
ILD & 10.5 & {$[0.7,0.75,0.9]$} & 102.16 & - & - \\
MA & 4.63 & {$[0.5,0.65,0.8]$} & 25.84 & - & - \\
\hline
\end{tabular}

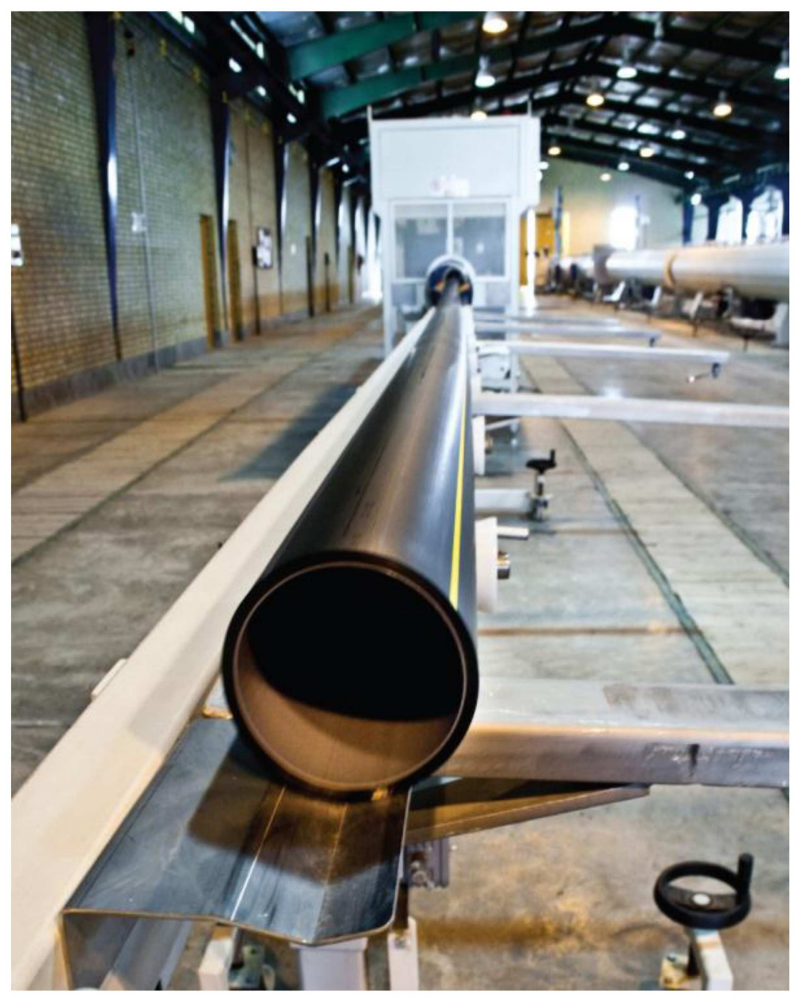

Figure 4. The production shop in SPP and F.

these three levels are equal to $(108902859,134883301$, 155675144), (127388473, 156915809, 180137255), and (159099140, 194737221, 222036669).

To determine a preferable solution, an aspiration membership function, $\mu_{G}$, is constructed as follows:

$$
\mu_{G}(x)= \begin{cases}\frac{222036669-x}{222036669}, & 0 \leq x \leq 222036669 \\ 0, & \text { otherwise }\end{cases}
$$

Applying Eq. (21), compatibility index of each solution with DMs aspiration, $\mu_{G}$, is computed as $K_{G}\left(z_{0.7}^{*}\right)=0.4003, K_{G}\left(z_{0.8}^{*}\right)=0.6036$, and $K_{G}\left(z_{0.8}^{*}\right)=$ 0.1355 . The membership of each decision in decision space is specified by Eq. (22) as $\mu_{D}\left(x_{0.7}^{*}\right)=0.28021$, $\mu_{D}\left(x_{0.7}^{*}\right)=0.48288$, and $\mu_{D}\left(x_{0.7}^{*}\right)=0.12195$. Finally, the optimal decision is selected with the highest degree in 0.8 satisfaction level.

In satisfaction level of 0.8 , the optimal master production plan is shown in Table 4 .

Note that as a result of the proposed model, the values of $c_{r t}$ in Table 4 , which show the net requirements of different resources in each period, can directly enter the process of material requirement planning.

As this problem is solved to create a suitable situation for production planning, the results of this planning are compared with the same period in the previous year, which illustrate the existing gaps between production amounts and the occurring sale as well as the purchased materials and consumed amounts. Consequently, the real data indicate that PP and ABS have been purchased 1.5 and 0.7 tons more than the required amounts, respectively, which lead to additional holding costs. On the other hand, some 
Table 2. Costs information.

\begin{tabular}{clll}
\hline Product & \multicolumn{1}{c}{$\tilde{\boldsymbol{c}}_{\boldsymbol{k}}^{p}$} & \multicolumn{1}{c}{$\tilde{\boldsymbol{c}}_{\boldsymbol{k}}^{h}$} & \multicolumn{1}{c}{$\tilde{\boldsymbol{c}}_{\boldsymbol{k}}^{b}$} \\
\hline BN & {$[16,19,32]$} & {$[2.4,2.85,4.8]$} & {$[17.76,21.09,35.52]$} \\
DSP & {$[15,18,23]$} & {$[1.5,1.8,2.3]$} & {$[16.65,19.98,25.53]$} \\
EBC & {$[17,21,25]$} & {$[3.4,4.2,4.6]$} & {$[18.02,22.26,26.5]$} \\
VPN & {$[90,100,150]$} & {$[22.5,25,37.5]$} & {$[103.5,115,172.5]$} \\
B & {$[120,139,152]$} & {$[12,13.9,15.2]$} & {$[130.8,151.51,165.68]$} \\
EC & {$[50,79,92]$} & {$[10,15.8,18.4]$} & {$[55.5,87.69,102.12]$} \\
O & {$[65,80,102]$} & {$[9.75,12,18.4]$} & {$[72.8,89.6,114.24]$} \\
A & {$[150,173,186]$} & {$[37.5,43.25,46.5]$} & {$[166.5,192.03,206.46]$} \\
E & {$[45,63,92]$} & {$[9,12.6,18.4]$} & {$[48.6,68.04,99.36]$} \\
DD & {$[80,109,118]$} & {$[12,16.35,17.7]$} & {$[90.4,123.17,133.34]$} \\
AD & {$[100,110,120]$} & {$[10,11,12]$} & {$[106,116.6,127.2]$} \\
SJ & {$[78,90,100]$} & {$[19.5,22.5,25]$} & {$[84.24,97.2,108]$} \\
P & {$[90,109,116]$} & {$[18,21.8,23.2]$} & {$[94.5,114.45,121.8]$} \\
BS & {$[68,79,90]$} & {$[6.8,7.9,9]$} & {$[76.16,88.48,100.8]$} \\
ILD & {$[20,35,42]$} & {$[5,8.75,10.5]$} & {$[21.4,37.45,44.94]$} \\
MA & {$[32,49,56]$} & {$[4.8,7.35,8.4]$} & {$[36.16,55.37,63.28]$} \\
\hline
\end{tabular}

products such as EBC, EC, DD, and SJ have been produced less than the demands and, on the contrary, DSP, VPN, D, BS, and ILD have been produced more than the required amounts; both diversions lead to remarkable backorder holding costs. However, with an $80 \%$ confidence, the proposed method does not impose any costs on demands not met and maintains holding costs at their lowest level.

Regarding these results, the production plan is determined as an exact guide for production managers. Also, a purchase manager can schedule their buying process according to these results.

\section{Conclusion}

Master production scheduling is a roadmap in the hands of production managers to schedule their operations and get the required materials and resources. Various parameters and variables are considered in MPS, like demand for products, cost parameters, material requirement parameters, capacity limitations, etc. These parameters usually face uncertainty and are not determined exactly. In this study, a model was proposed to deal with the situation; in the model, demands for products behaved stochastically, while cost and resource utilization parameters were determined as fuzzy numbers. These assumptions are logical in practical situations. While demand followed a timedependent behavior, which could be captured soundly with probability distributions, the cost and capacity constraints dealt with recognition-based uncertainty, due to lack of knowledge, and could be handled with fuzziness. The problem was modeled and its solution approach was proposed based on an interactive procedure, in which the formulated MPS problem was solved in different satisfaction levels; finally, the preferable solution was chosen based on aspiration of the decision maker. The results of the proposed method determined the production scheduling and magnitude of different products of the manufacturer in each period. Also, one of the advantages of the model was the possibility to determine the material net requirement in each period, which could be used directly in material requirement planning. Application of the proposed model was shown in a real-world case study consisting in production scheduling of 16 products with stochastic demand in a time horizon of 3 months. The best results were obtained at a satisfaction level of 0.8. The proposed method had a good conformity with real situations, in which demand for products had a stochastic nature and cost parameters were not determined exactly. Another advantage of the proposed model was its feasibility to accept new restrictions such as warehouse space, outsourcing, etc. This model can be applied in manu- 
Table 3. Products demand information for a three-month period.

\begin{tabular}{|c|c|c|c|c|c|}
\hline \multirow{2}{*}{ Product } & \multirow{2}{*}{$\begin{array}{l}\text { Probability } \\
\text { distribution }\end{array}$} & \multirow{2}{*}{ Parameter } & \multicolumn{3}{|c|}{ Months (Ton) } \\
\hline & & & 1 & 2 & 3 \\
\hline \multirow{2}{*}{$\mathrm{BN}$} & \multirow{2}{*}{ Weibull } & Shape & 1.6125 & 1.8 & 1.5 \\
\hline & & Scale & 46045 & 44320.5 & 47342 \\
\hline \multirow{2}{*}{ DSP } & \multirow{2}{*}{ Normal } & Mean & 19217 & 18500 & 20562 \\
\hline & & Variance & 166916 & 124568 & 103791 \\
\hline \multirow{2}{*}{$\mathrm{EBC}$} & \multirow{2}{*}{ Weibull } & Shape & 1.7238 & 1.982 & 2.045 \\
\hline & & Scale & 6032 & 7000.32 & 8931 \\
\hline VPN & Poisson & Mean & 2560 & 2800 & 2011 \\
\hline \multirow{2}{*}{ B } & \multirow{2}{*}{ Normal } & Mean & 30966 & 28690.7 & 32019 \\
\hline & & Variance & 191068 & 145678.2 & 58960 \\
\hline \multirow{2}{*}{ EC } & \multirow{2}{*}{ Logistic } & Location & 51929 & 47542 & 72940 \\
\hline & & Scale & 4772 & 3864 & 2901 \\
\hline \multirow{2}{*}{$\mathrm{O}$} & \multirow{2}{*}{ Normal } & Mean & 44694 & 51203 & 65789 \\
\hline & & Variance & 53790 & 68700 & 80173 \\
\hline A & Exponential & Mean & 58568 & 46400 & 28304 \\
\hline \multirow{2}{*}{$\mathrm{E}$} & \multirow{2}{*}{ Normal } & Mean & 21587 & 18700 & 32570 \\
\hline & & Variance & 19934 & 13456 & 21723 \\
\hline DD & Exponential & Mean & 20125 & 29340 & 17811 \\
\hline \multirow{2}{*}{$\mathrm{AD}$} & \multirow{2}{*}{ Uniform } & Lower bound & 10000 & 8500 & 13000 \\
\hline & & Upper bound & 15000 & 12000 & 17000 \\
\hline \multirow{2}{*}{ SJ } & \multirow{2}{*}{ Log logistic } & Location & 9.33 & 10.465 & 11 \\
\hline & & Scale & 0.1989 & 0.3 & 0.45 \\
\hline \multirow{2}{*}{$\mathrm{P}$} & \multirow{2}{*}{ Lognormal } & Location & 8.18 & 9.15 & 10 \\
\hline & & Scale & 0.6344 & 0.6987 & 0.8019 \\
\hline \multirow{2}{*}{ BS } & \multirow{2}{*}{ Logistic } & Location & 51925 & 61248 & 40890 \\
\hline & & Scale & 26997 & 29896 & 31075 \\
\hline \multirow{2}{*}{ ILD } & \multirow{2}{*}{ Normal } & Mean & 31820 & 37658 & 35941 \\
\hline & & Variance & 47917 & 54210 & 63183 \\
\hline MA & Constant & & 24000 & 20000 & 19800 \\
\hline
\end{tabular}


Table 4. Optimal production plan at satisfaction level of 0.8 .

\begin{tabular}{|c|c|c|c|c|c|c|c|}
\hline \multirow{2}{*}{ Product } & \multicolumn{3}{|c|}{ Months (Ton) } & \multirow{2}{*}{ Material } & \multicolumn{3}{|c|}{ Months (Ton) } \\
\hline & 1 & 2 & 3 & & 1 & 2 & 3 \\
\hline $\mathrm{BN}$ & 61853 & 57733 & 65018 & PP & 15.81 & 16.35 & 16.35 \\
\hline DSP & 19561 & 18797 & 20834 & Polyacetal & 0.93 & 1.01 & 1.37 \\
\hline $\mathrm{EBC}$ & 7950 & 8901 & 11278 & ABS & 0.14 & 1.58 & 0.00 \\
\hline VPN & 2603 & 2845 & 2049 & Material & \multicolumn{3}{|c|}{ Months (Ton) } \\
\hline B & 31084 & 29012 & 32224 & holding & 1 & 2 & 3 \\
\hline $\mathrm{EC}$ & 58545 & 52899 & 76962 & PP & 0 & 0 & 0 \\
\hline $\mathrm{O}$ & 44890 & 51424 & 66028 & Polyacetal & 0 & 1.07 & 0 \\
\hline A & 94262 & 74678 & 45554 & ABS & 0 & 0 & 0 \\
\hline $\mathrm{E}$ & 21706 & 18798 & 32694 & \multicolumn{4}{|c|}{ - The results are rounded upward. } \\
\hline DD & 32390 & 47221 & 28666 & & & & \\
\hline $\mathrm{AD}$ & 14000 & 11300 & 16200 & & & & \\
\hline SJ & 14935 & 53151 & 111729 & & & & \\
\hline $\mathrm{P}$ & 6088 & 16951 & 43257 & & & & \\
\hline BS & 89351 & 102693 & 84843 & & & & \\
\hline ILD & 32005 & 37854 & 36153 & & & & \\
\hline MA & 24000 & 20000 & 19800 & & & & \\
\hline
\end{tabular}

facturing companies that produce multiple products; the companies whose critical issue is planning and scheduling of the products and getting the required resources. Future researches can be focused on formulating multi-objective production planning models considering other objectives like production progress.

\section{References}

1. Higgins, P. and Browne, J. "Master production scheduling: a concurrent planning approach", Production Planning and Control, 3(1), pp. 2-18 (1992).

2. Tubino, D.F., Manual of Production Planning and Control [Manual de planejamento e controle da produçño], Sao Paulo, Atlas (2000).

3. Soares, M.M. and Vieira, G.E. "A new multi-objective optimization method for master production scheduling problems based on genetic algorithm", International Journal of Advanced Manufacturing Technology, 41(5), pp. 549-567 (2009).

4. Cox, J.F. and Blackstone, J.H., APICS Dictionary, Virginia: APICS (2001).

5. Houghton, E. and Portugal, V. "Optimum production planning: an analytic framework", International Journal of Operations and Production Management, 21(9), pp. 1205-1221 (2001).

6. Vasant, P.M. "Application of fuzzy liner programming in production planning", Fuzzy Optimization and Decision Making, 2(3), pp. 229-241 (2003).
7. Wang, H.F. and Wu, K.Y. "Modeling and analysis for multi-period, multi-product and multi-resource production scheduling", Journal of Intelligent Manufacturing, 14(3), pp. 297-309 (2003).

8. Emani Vieira, G. and Ribas, P.C. "A new multiobjective optimization method for master production scheduling problems using simulated annealing", International Journal of Production Research, 42(21), pp. 4609-4622 (2003).

9. Sawik, T. "Multi-objective master production scheduling in make-to-order manufacturing", International Journal of Production Research, 45(12), pp. 2629-2653 (2007).

10. Lei, D. "Multi-objective production scheduling: a survey", International Journal of Advanced Manufacturing Technology, 43, pp. 926-938 (2009).

11. Leu, J.D., Wen, T.C., and Chang, K.H. "Development and application of a decision model for the integrated production and material planning of color filter manufacturing industry: an empirical study", International Journal of Industrial Engineering: Theory, Application and Practice, 17(4), pp. 300-309 (2011).

12. Kelbel, J. and Hanzalek, Z. "Solving production scheduling with earliness/tardiness penalties by constraint programming", Journal of Intelligent Manufacturing, 22(4), pp. 553-562 (2011).

13. Alfieri, A., Tolio, T., and Urgo, M. "A project scheduling approach to production and material requirement planning in manufacturing-to-order environments", 
Journal of Intelligent Manufacturing, 23(3), pp. 575585 (2012).

14. Alfieri, A., Tolio, T., and Urgo, M. "A two-stage stochastic programming project scheduling approach to production planning", International Journal of $A d$ vanced Manufacturing Technology, 62(1), pp. 279-290 (2012).

15. Ballestin, F., Mallor, F., and Mateo, P.M. "Production scheduling in a market-driven foundry: a mathematical programming approach versus a project scheduling metaheuristic algorithm", Optimization and Engineering, 13(4), pp. 663-687 (2012).

16. Moon, J.Y., Shin, K., and Park, J. "Optimization of production scheduling with time-dependent and machine-dependent electricity cost for industrial energy efficiency", International Journal of Advanced Manufacturing Technology, 68(1), pp. 523-535 (2010).

17. Sun, L.B., Gao, S.S., Tao, S.Q., Li, Y.B., and Du, B.G. "A master production schedule warning approach for cement equipment manufacturing enterprises", Scientia Iranica Transactions E: Industrial Engineering, 21(3), pp. 1120-1127 (2014).

18. Sahebjamnia, N., Jolai, F., Torabi, S.A., and Aghabeiglo, M. "A novel fuzzy stochastic multi-objective linear programming for multi-level capacitated lot-sizing problem: a real case study of a furniture company", The International Journal of Advanced Manufacturing Technology, 84(1-4), pp. 749-767 (2016).

19. Kim, S.H. and Lee, Y.H. "Synchronized production planning and scheduling in semiconductor fabrication", Computers and Industrial Engineering, 96, pp. 72-85 (2016).

20. Menezes, G.C., Mateus, G.R., and Ravetti, M.G. "A hierarchical approach to solve a production planning and scheduling problem in bulk cargo terminal", Computers and Industrial Engineering, 97, pp. 1-14 (2016).

21. Martinez, K.Y.P., Morabito, R., and Toso, E.A.V. "Production planning in the molded pulp packaging industry", Computers and Industrial Engineering, 98, pp. 554-566 (2016).

22. Radhika, S., Srinivasa Rao, Ch., Neha Krishna, D., and Karteeka Pavan, K. "Multi-objective optimization of master production scheduling problems using Jaya algorithm", Proceeding of 6th International \& 27th All India Manufacturing Technology, Design and Research Conference (AIMTDR-2016), pp. 1729-1732 (2016).

23. Cho, H.M. and Jeong, C.J. "A two-level method of production planning and scheduling for bi-objective reentrant hybrid flow shops", Computers \& Industrial Engineering, 107, pp. 174-181 (2017).

24. Farrokh, M., Azar, A., Jandaghi, G., and Ahmadi, E. "A novel robust fuzzy stochastic programming for closed loop supply chain network design under hybrid uncertainty", Fuzzy Sets and Systems, 341, pp. 69-91 (2018).

25. Gramani, M.C.N., França, P.M., and Arenales, M.N. "A linear optimization approach to the combined production planning model", Journal of the Franklin Institute, 348(7), pp. 1523-1536 (2011).

26. Yovits, M.C., Advances in Computers, 23, Academic, Gainesville, FL (1984).

27. Pedrycz, W. and Gomide, F., An Introduction to Fuzzy Sets: Analysis and Design, Massachusetts: Massachusetts Institute of Technology (1998).

28. Tang, O. and Grubbstrom, R.W. "Planning and replanning the master production schedule under demand uncertainty", International Journal of Production Economics, 78(3), pp. 323-334 (2002).

29. Fleten, S.E. and Kristoffersen, T.K. "Short-term hydropower production planning by stochastic programming", Computers and Operation Research, 35(8), pp. 2656-2671 (2008).

30. Feng, K., Rao, U.S., and Raturi, A. "Setting planned orders in master production scheduling under demand uncertainty", International Journal of Production Research, 49(13), pp. 4007-4025 (2011).

31. Liang, T.F. "Fuzzy multi-objective production/ distribution planning decisions with multi-product and multi-time period in supply chain", Computers and Industrial Engineering, 55(3), pp. 676-694 (2008).

32. Supriyanto, I. and Noche, B. "Fuzzy multi-objective linear programming and simulation approach to the development of valid and realistic master production schedule", Logistics Journal: Proceeding, 7 pp. 1-14 (2011).

33. Körpeoğlu, E., Yaman, H., and SelimAktürk, M. "A multi-stage stochastic programming approach in master production scheduling", European Journal of Operational Research, 213(1), pp. 166-179 (2011).

34. Mula, J., Poler, R., Garcia-Sabater, J.P., and Lario, F.C. "Models for production planning under uncertainty: a review", International Journal of Production Economics, 103(1), pp. 271-285 (2006).

35. Wang, C. and Qiu, Z. "Hybrid uncertain analysis for temperature field prediction with random, fuzzy and interval parameters", International Journal of Thermal Sciences, 98, pp. 124-134 (2015).

36. Wang, C., Qiua, Z., and He, Y. "Fuzzy stochastic finite element method for the hybrid uncertain temperature field prediction", International Journal of Heat and Mass Transfer, 91, pp. 512-519 (2015).

37. Wang, C., Qiu, Z., and He, Y. "Fuzzy interval perturbation method for uncertain heat conduction problem with interval and fuzzy parameters", International Journal for Numerical Methods in Engineering, 104(5), pp. 330-346 (2015).

38. Wang, C., Qiu, Z., Xu, M., and Li, Y. "Novel reliability-based optimization method for thermal structure with hybrid random, interval and fuzzy parameters", Applied Mathematical Modelling, 47, pp. 576-586 (2017).

39. Charnes, A. and Cooper, W.W. "Chance-constrained programming", Management Science, 6(1), pp. 73-79 (1959). 
40. Zhu, M., Taylor, D.B., Sarin, S.C., and Kramer, R.A. "Chance constrained programming models for riskbased economic and policy analysis of soil conservation", Agricultural and Resource Economics Review, 23(1), pp. 58-65 (1994).

41. Zadeh, L. "Fuzzy sets", Information Control, 8, pp. 338-353 (1965).

42. Kaufmann, A. and Gupta, M.M., Introduction to Fuzzy Arithmetic: Theory and Applications, New York: Van Nostrand Reinhold (1991).

43. Cao, B.Y., Wang, G.J., Guo, S.Z., and Chen, S.L., Fuzzy Information and Engineering, Heidelberg: Springer-Verlag (2010).

44. Lee, K.H., First Course on Fuzzy Theory and Applications, Berlin, Heidelberg: Springer-Verlag (2005).

45. Chandra, S. and Aggarwal, A. "On solving linear programming problems: A revisit to Zimmermann's approach", Journal of Intelligent Fuzzy Systems, 27(5), pp. 2603-2610 (2014).

46. Guua, S.M. and Wu, Y.K. "Two-phase approach for solving the fuzzy linear programming problems", Fuzzy Set Systems, 107(2), pp. 191-195 (1999).

47. Jimenez, M., Arenas, M., Bilbao, A., and Rodriguez, M.V. "Linear programming with fuzzy parameters: an interactive method resolution", European Journal of Operational Research, 177(3), pp. 1599-1609 (2007).

48. Kaur, J. and Kumar, A. "A new method to find the unique fuzzy optimal value of fuzzy linear programming problems", Journal of Optimization Theory and Applications, 156(2), pp. 529-534 (2013).

49. Kumar, A., Kaur, J., and Singh, P. "A new method for solving fully fuzzy linear programming problems", Applied Mathematical Modelling, 35(2), pp. 817-823 (2011).

50. Li, B., Theory and Practice of Uncertain Programming, Berlin - Heidelberg (2009).

51. Ouarda, T.B.M.J. and Labadie, J.W. "Chanceconstrained optimal control for multireservoir system optimization and risk analysis", Stochastic Environmental Research and Risk Assessment, 15(3), pp. 185204 (2001).
52. Ding, X. and Wang, C. "A novel algorithm of stochastic chance-constrained linear programming and its application", Mathematical Problems in Engineering, 2012, pp. 1-17 (2012).

53. Ishibuchi, H. and Tanaka, H. "Multi objective programming in optimization of the interval objective function", European Journal of Operational Research, 48(2), pp. 219-225 (1990).

54. Kaufmann, A. and Gil Aluja, J., Técnicas de Gestión de Empresa, Madrid: Pirámide (1992).

55. Yager, R.R. "Ranking fuzzy subsets over the unit interval", In Proceedings of 17th IEEE International Conference on Decision and Control, San Diego, CA, pp. 1435-1437 (1979).

\section{Biographies}

Seyed Hossein Razavi Hajiagha received his $\mathrm{PhD}$ in Industrial Management from Allameh Tabatabaei University and is now Assistant Professor at Khatam University. $\mathrm{He}$ is an editorial board member and reviewer of several international journals and has been the chairman of several international conferences. His research interests are in the areas of MADM, operational research, and DEA.

Shide Sadat Hashemi received her MA in Industrial Management from Allameh Tabatabaei University. She is the executive manager of Saramadan Andishe AVINA Co. and has been the senior member of consultant teams in different managerial projects. She is reviewer of some international journals. Her research interests are BPMN, strategy, MCDM, and FS.

Mohammadreza Sadeghi received his PhD in Industrial Management from Allameh Tabatabaei University. He is the manager of the managerial research team in Sa-Avina Co. He has authored several international papers and managed many managerial projects in MCDM, DEA, and production planning. 